\title{
Effect of high-latitude ionospheric convection on Sun-aligned polar caps
}

\author{
J. J. Sojka, L. Zhu, D. J. Crain, and R. W. Schunk \\ Center for Atmospheric and Space Sciences, Utah State University, Logan
}

Abstract. A coupled magnetospheric-ionospheric (M-I) MHD model has been used to simulate the formation of Sun-aligned polar cap arcs for a variety of interplanetary magnetic field (IMF) dependent polar cap convection fields. The formation process involves launching an Alfvén shear wave from the magnetosphere to the ionosphere where the ionospheric conductance can react self-consistently to changes in the upward currents. We assume that the initial Alfvern shear wave is the result of solar wind-magnetosphere interactions. The simulations show how the $E$ region density is affected by the changes in the electron precipitation that are associated with the upward currents. These changes in conductance lead to both a modified Alfvén wave reflection at the ionosphere and the generation of secondary Alfvén waves in the ionosphere. The ensuing bouncing of the Alfvén waves between the ionosphere and magnetosphere is followed until an asymptotic solution is obtained. At the magnetosphere the Alfvén waves reflect at a fixed boundary. The coupled M-I Sun-aligned polar cap arc model of Zhu et al. (1993a) is used to carry out the simulations. This study focuses on the dependence of the polar cap arc formation on the background (global) convection pattern. Since the polar cap arcs occur for northward and strong $B_{y}$ IMF conditions, a variety of background convection patterns can exist when the arcs are present. The study shows that polar cap arcs can be formed for all these convection patterns; however, the arc features are dramatically different for the different patterns. For weak sunward convection a relatively confined single pair of current sheets is associated with the imposed Alfvén shear wave structure. However, when the electric field exceeds a threshold, the arc structure intensifies, and the conductance increases as does the local Joule heating rate. These increases are faster than a linear dependence on the background electric field strength. Furthermore, above the threshold, the single current sheet pair splits into multiple current sheet pairs. For the fixed initial ionospheric and magnetospheric conditions used in this study, the separation distance between the current pairs was found to be almost independent of the background electric field strength. For either three-cell or distorted two-cell background convection patterns the arc formation favored the positive $B_{y}$ case in the northern hemisphere.

\section{Introduction}

At high latitudes, poleward of the auroral region, auroral forms are observed. These auroral structures have a diverse terminology, that is, polar cap arcs, extremely high latitude auroras, sun-aligned arcs, transpolar arcs, and theta auroras. In this theoretical study these forms are indistinguishable and we will use the term Sun-aligned arc (SA) to describe a Sun-aligned auroral form located in the polar cap. The occurrence of SA at very high geomagnetic latitudes was reported [Weill, 1958; Davis, 1960, 1963; Denholm and Bond, 1961] when the first systematic morphological study of auroras in the oval region began [cf. Akasofu, 1964]. In contrast with the arcs in the auroral oval, which are strongly correlated with a southward interplanetary magnetic field (IMF), the SA at very high latitudes were mostly observed during periods of northward IMF [Berkey et al., 1976; Ismail et al., 1977; Lassen and Danielsen, 1978]. The SA can be very bright and can even cross the polar cap from the dayside to the nightside of the

Copyright 1994 by the American Geophysical Union.

Paper number 93JA02667.

0148-0227/94/93JA-02667\$05.00 auroral oval to form a pattern that looks like the Greek letter theta [Frank et al., 1982, 1986; Nielsen et al., 1990]. However, they can also be confined to the polar cap and remain relatively weak, can display multiple discrete patterns, and can be located either in the evening or morning sector of the polar cap [Weber and Buchau, 1981; Ismail and Meng, 1982; Murphree et al., 1982, Gussenhoven, 1982; Carlson et al., 1984; Rich et al., 1990].

Sun-aligned arcs have been found under different polar cap convection conditions. The convection patterns associated with the arcs can be a mesoscale shear flow pattern [Hoffman et al., 1985; Carlson et al., 1988; Valladares and Carlson, 1991], a large-scale sunward flow pattern [Frank et al., 1986], or an ambiguous and confused pattern [Rich et al., 1990]. One general consensus in the observations of the SA is that the arcs are associated with upward field-aligned currents which are carried by energetic precipitating electrons [Hardy et al., 1982; Valladares and Carlson, 1991]. The dependence of the SA on the $Y$ component of the IMF has also been reported by researchers [e.g., Meng, 1981; Gussenhoven, 1982; Makita et al., 1991].

Theoretical studies of SA are still in the early stages. Most of the relevant work was concerned with the global-scale ionospheric convection pattern and the large-scale current 
configuration during northward IMF conditions and their coupling to the magnetosphere [Russell, 1972; Maezawa, 1976; Burke et al., 1979; Potemra et al., 1984; Chiu et al., 1985; Reiff and Burch, 1985; Burch et al., 1985; Rasmussen and Schunk, 1987; Marklund and Blomberg, 1991]. Only a small portion of the theoretical effort was focused on the SA structures and their corresponding dynamical processes. On the basis of S3-2 data, Burke et al. [1982] proposed a model for SA occurring on open field lines. By introducing the concept of a multiple bifurcation of magnetic field lines, Kan and Burke [1985] constructed a model of SA and proposed that theta aurora can occur on closed field lines, and the less intense SA can occur either on closed or open field lines. Chiu [1989] formulated a model of SA assuming that they occur on open field lines and that their formation is due to the current response to mesoscale velocity shear structures in the ionosphere. All these models are somewhat limited in that they are either qualitative, semi-quantitative, or steady state models.

Recently, Zhu et al. [1993a] developed a time-dependent coupled magnetosphere-ionosphere (M-I) model of SA. This model uses the technique devised by Chiu [1989] in which a velocity shear structure is imposed on the ionosphere and the resulting current system gives rise to the SA. The primary Alfvén wave carrying the initial shear structure is imposed on the ionosphere from the magnetosphere. The M-I SA model of Zhu et al. [1993a] follows the time evolution of Alfvén waves propagating between the ionosphere and magnetosphere. The effect of wave-wave interaction as these Alfvén waves propagate between the ionosphere and magnetosphere is not considered in this model. This may lead to differences from a fully interacting system. In this model, the new key element is that the ionospheric conductance can respond to changes in the field-aligned current. The changes in the ionospheric conductance lead to the generation of secondary Alfvén waves. This new model produced some very interesting quantitative results; a short timescale for arc formation (around $10 \mathrm{~min}$ ), cross-arc plasma transport, arc currents that close locally, and the tendency for the single SA to split into multiple structures. However, these initial model studies were performed with an antisunward background convection pattern, which is more typical of southward IMF conditions.

The focus of this study is to quantitatively investigate the dependence of the Zhu et al. [1993a] M-I SA model on more realistic northward and strong $B_{y}$ IMF conditions. Section 2 describes the model, while section 3 presents proposed northward IMF convection patterns as well as the simplified convection patterns we adopt for this study. The M-I SA model is run for a variety of these background convection patterns and the results are presented in section 4 . The model results and predictions are summarized in section 5 .

\section{Coupled M-I Sun-Aligned Arc Model}

The Utah State University coupled magnetosphereionosphere model of Sun-aligned arcs [Zhu et al., 1993a] is used in this study. The theoretical development, numerical techniques, and initial simulation results have been extensively described by Zhu et al. [1993a], and hence only key aspects of this model are discussed here. The coupled M-I SA model is a time-dependent MHD model that describes the Alfvén wave propagation and reflection between a twodimensional magnetosphere and a two-dimensional ionosphere coupled by equipotential field lines. In the simulations the upward field-aligned currents are associated with electron precipitation, which dynamically modifies the ionospheric conductance. The temporal changes of the twodimensional height-integrated conductivity lead both to modifications in the Alfvén wave reflection characteristics and to the excitation of "secondary" Alfvén waves in the ionosphere. The combination of these two effects leads to a nonlinear response of the ionosphere in the MHD M-I electrodynamics.

In the first study, Zhu et al. [1993a] found that even with several simplifying assumptions, such as a magnetospheric boundary condition corresponding to an open magnetopause, a constant background antisunward convection in the ionosphere, and a simple initial conductance model that linearly decreases in the antisunward direction, a variety of detailed spatial and temporal variations were generated in the ionosphere in response to the imposed Alfvén wave that initiated the Sun-aligned arc. Of particular significance was the generation of a cross-arc convection component from a simulation in which the initial convection was purely antisunward and parallel to the imposed shear. In addition to the generation of a cross flow, there were asymmetries in the field-aligned currents, conductances, and Joule heating from the dawnside to the duskside of the SA. The details of how this cross-arc asymmetry, or more specifically, how the electrodynamics can develop an electric field component along the SA arc direction, are presented by Zhu et al. [1993b]. The cross component is derived from the dynamic changes of the conductivity which enable conductivity gradients to form transverse to the original conductivity gradient, which is also the direction of the imposed shear structure.

In addition to these features, a degree of "fine structuring" of the current system was found. This structuring took the form of parallel current sheets along the imposed shear structure axis. The scale of this structure was smaller than that of the imposed magnetospheric shear structure.

The equation describing the dynamic changes of the conductivity in the coupled M-I SA model [Zhu et al., 1993a] is derived from the continuity equation, in which both fieldaligned current term (first term on the right side) and convective term (last term on the right side) are included. The equation can be expressed as

$$
\begin{array}{r}
\frac{\partial \Sigma_{H}}{\partial t}=\frac{(Q H+1)}{B_{\mathrm{o}}} \nabla \cdot\left(\Sigma_{p} \mathbf{E}_{\mathrm{i}}+\Sigma_{H} \mathbf{b}_{\mathrm{o}} \times \mathbf{E}_{\mathbf{i}}\right)+\frac{e H}{B_{\mathrm{o}}} S_{\mathrm{o}}- \\
\frac{\beta B_{\mathrm{o}}}{e H} \Sigma_{H}^{2}+\nabla \Sigma_{H} \bullet \frac{\mathbf{b}_{\mathrm{o}} \times \mathbf{E}_{\mathbf{i}}}{B_{\mathrm{o}}}
\end{array}
$$

where $Q$ is the ionization coefficient, $H$ is the effective thickness of the conducting ionosphere, $B_{\mathrm{O}}$ is the background magnetic field, $\mathbf{E}_{\mathbf{i}}$ is the total ionospheric electric field, $\beta$ is the recombination coefficient, $\mathbf{b}_{\mathbf{0}}$ is the unit vector of the background magnetic field, and $\Sigma_{P}$ and $\Sigma_{H}$ are the ionospheric Pedersen and Hall conductances, respectively.

In the initial study an antisunward background convection pattern was used. Such a background convection pattern is not the most probable convection pattern in the presence of SA. Hence this study focuses on more realistic background convection patterns. The other parameters of the coupled M-I SA model are the same as described by Zhu et al. [1993a]. A background ionospheric height-integrated Hall conductance, 
which varies from 1.5 (noon) to 0.5 mho (midnight), is used. This corresponds to winter, solar maximum conditions. The simulations are carried out in the northern hemisphere for a rectangular simulation region that is centered on the magnetic pole and that extends $3000 \mathrm{~km}$ in the noon-midnight direction and $1000 \mathrm{~km}$ in the dawn-dusk direction. At the beginning of simulations we impose a magnetosphere originated shear flow to the coupled M-I system. This type of shear flow associated with polar cap arcs has been observed by many people [Mende et al., 1988; Valladares and Carlson, 1991]. However, the originating mechanism of such a shear flow is unclear at this time, although Lyons [1980] did extrapolate an auroral shear mechanism into the polar cap. Our imposed shear structure lies along the noon-midnight direction passing through the magnetic pole. The initial magnetospheric shear flow carried by the propagating Alfvén waves is represented by a potential in the form of a Gaussian distribution, as shown by the solid line in Figure 1. The shear flow is uniform in the noonmidnight direction. The corresponding electric field distribution, which is convergent in the center and divergent on the edges of the shear flow, is shown by the dashed line in Figure 1. The convergent electric field is a necessary condition for the existence of the electron precipitation associated with polar cap arcs [Valladares and Carlson, 1991]. The electric field peaks at $18 \mathrm{mV} / \mathrm{m}$ at a distance of $70 \mathrm{~km}$ from the center of the shear structure. This gives the structure a characteristic width of around $150 \mathrm{~km}$. In this study the initial shear flow remains the same for all runs. The study of the effect of various magnetospheric drivers on the mesoscale features of polar cap arcs will be the follow-up work of this study.

\section{Convection Models for Various IMF Conditions}

As described in the introduction, SAs are associated with northward or strong $B_{y}$ IMF conditions. Under these circumstances the background convection pattern in the polar cap has great diversity and has been represented by various patterns. These patterns have been pieced together using statistical techniques from a large database of satellite and

INITIAL PERTURBATION

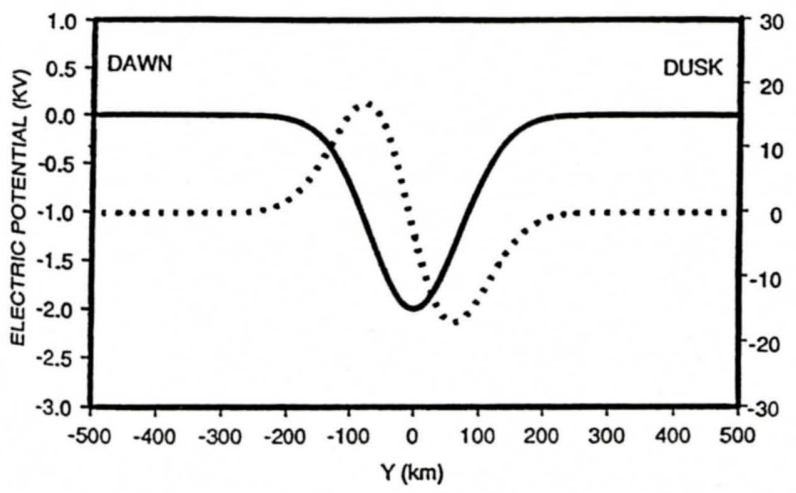

Figure 1. Potential distribution in the dawn-dusk cross section associated with the initial magnetospheric shear flow (solid line) and the corresponding electric field distribution (dashed line). ground-based observations, as well as from topological modeling of the magnetosphere. However, none of the currently available patterns are instantaneous snapshots of the polar cap convection. Hence for this study we will use the most basic components of these convection patterns as a representation of the background convection upon which the SA shear structure is superimposed at the start of the simulation. For each simulation a specific feature of the background convection is studied for its impact on the ensuing SA formation.

Figure 2 shows six schematic convection patterns (polar dial plots) and the corresponding convection used in the polar cap simulation (rectangular plots). The top left pattern represents the classical Volland two-cell convection pattern. This was used in the Zhu et al. [1993a] coupled M-I SA development study. In our study the background convection electric field strength is $20 \mathrm{mV} / \mathrm{m}$ and the plasma convects antisunward and parallel to the imposed shear structure. Such a pattern would normally be associated with southward IMF conditions. The top right panel of Figure 2 show the case of four-cell convection. Such a pattern has been inferred from many observations for strongly northward IMF conditions, that is, Burke et al. [1979]; Potemra et al. [1984], and Reiff and Burch [1985]. For the purposes of this study the
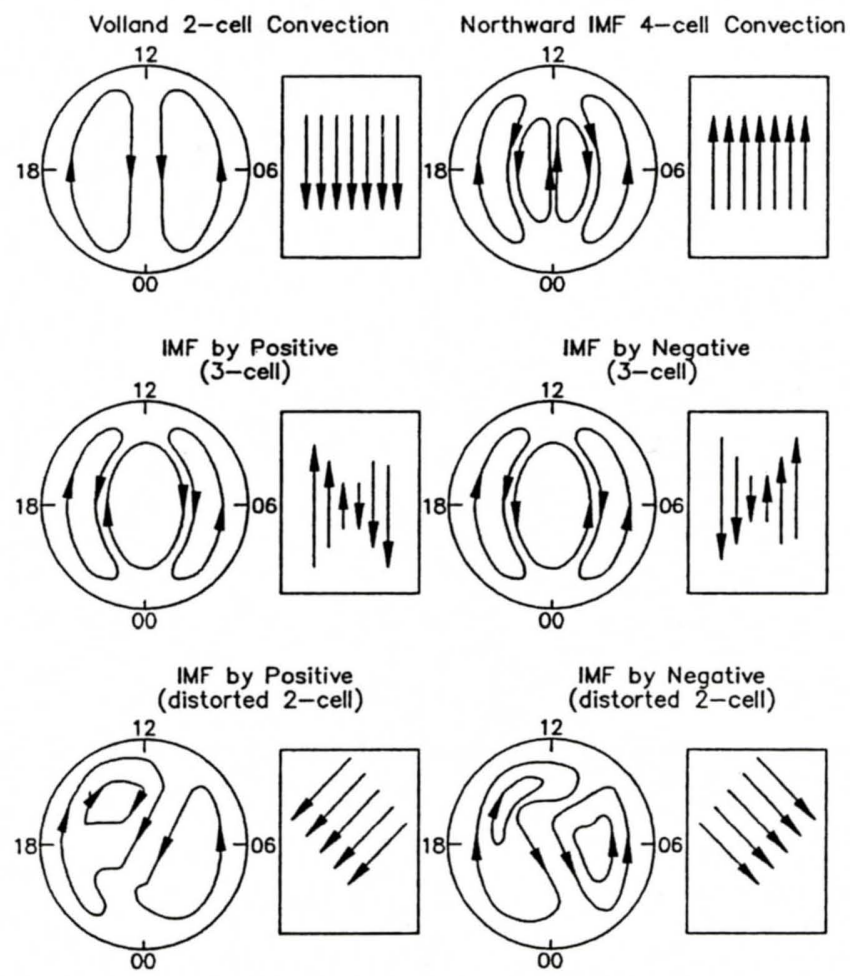

Figure 2. Schematic representations of the high-latitude interplanetary magnetic field dependent convection patterns (dial plots) and the corresponding simplified polar cap convection patterns adopted in the simulations (rectangular plots). In each case the rectangular plot represents the prevailing convection pattern at high latitudes, that is, the central region of the polar dial pattern. The rectangular plots have the same local time orientation as the dial plots, while the dimensions of the rectangular plots are the simulation boundaries which are described in the text. 
simulation uses a uniform sunward convection pattern with an electric field magnitude in the 5- to $30-\mathrm{mV} / \mathrm{m}$ range.

When the IMF $B_{y}$ component dominates, the dawn-dusk symmetry shown in the top two panels of Figure 2 is removed. Both Potemra et al. [1984] and Reiff and Burch [1985] show how a three-cell pattern is present during conditions of slightly northward IMF when $B_{y}$ is large. These three-cell patterns are shown in the middle panels of Figure 2. The left middle panel is for positive $B_{y}$ while the right middle panel is for negative $B_{y}$. In each case this is simulated by a Sunaligned flow reversal from sunward to antisunward, but the reversal is not a strong shear. At the dawn and dusk edges of the simulation region the electric field magnitude reaches 28 $\mathrm{mV} / \mathrm{m}$.

An alternative set of patterns has been presented by Heppner and Maynard [1987] for the case of strong IMF $B_{y}$ conditions in which the IMF is weakly northward. These are described as distorted two-cell patterns; the main feature of which is that the Sun-aligned orientation is no longer present. Such distorted convection patterns are shown in the bottom panels of Figure 2. The left patterns are for positive $B_{y}$, while the right panels are for negative $B_{y}$ conditions. In the simulations, these patterns are represented by a uniform, but oblique, convection pattern, that is, aligned at $45 \mathrm{deg}$ to the direction of the imposed SA structure. As a result, these two convection patterns will have a "cross flow" convection component. The magnitude of the electric field is $20 \mathrm{mV} / \mathrm{m}$. This basic oblique convection pattern is also consistent with the polar cap convection suggested by Reiff and Burch [1985] for strong $B_{y}$ and weakly southward IMF conditions. In the following sections the coupled M-I model will be run for winter, solar maximum conditions using these simplified "simulation" convection patterns.

\section{M-I Arc Simulations for Various Background Convection Patterns}

\subsection{Sunward Versus Antisunward Background Convection}

In the Zhu et al. [1993a] study a background antisunward convection pattern was adopted. In the polar cap the dawndusk electric field was uniform and equal to $20 \mathrm{mV} / \mathrm{m}$, which corresponded to an antisunward plasma convection speed of about $400 \mathrm{~m} / \mathrm{s}$. As discussed in section 3, SAs are usually associated with northward IMF conditions and the convection patterns are typically more complex than that used in the $Z h u$ et al. [1993a] study. A common feature of these patterns is that they display a significant sunward convection component. The first step in this study is to reverse the dawnto-dusk background convection electric field and repeat the SA simulation.

Figures $3 \mathrm{a}$ and $3 \mathrm{~b}$ show the asymptotic field-aligned currents associated with the SAs for the earlier Zhu et al. [1993a] antisunward convection and our sunward convection patterns, respectively. The $X$ axis represents the midnight-tonoon direction, while the $Y$ axis represents the dawn-to-dusk direction. Upward currents are represented by dashed contours and downward currents by the solid contours. In Figure $3 a$, two pairs of current sheets are readily distinguishable, with each current sheet having a peak current density that exceeds 12 $\mu \mathrm{A} / \mathrm{m}^{2}$ l. These two pairs of current sheets almost extend the entire noon-to-midnight distance. The most dawnward current

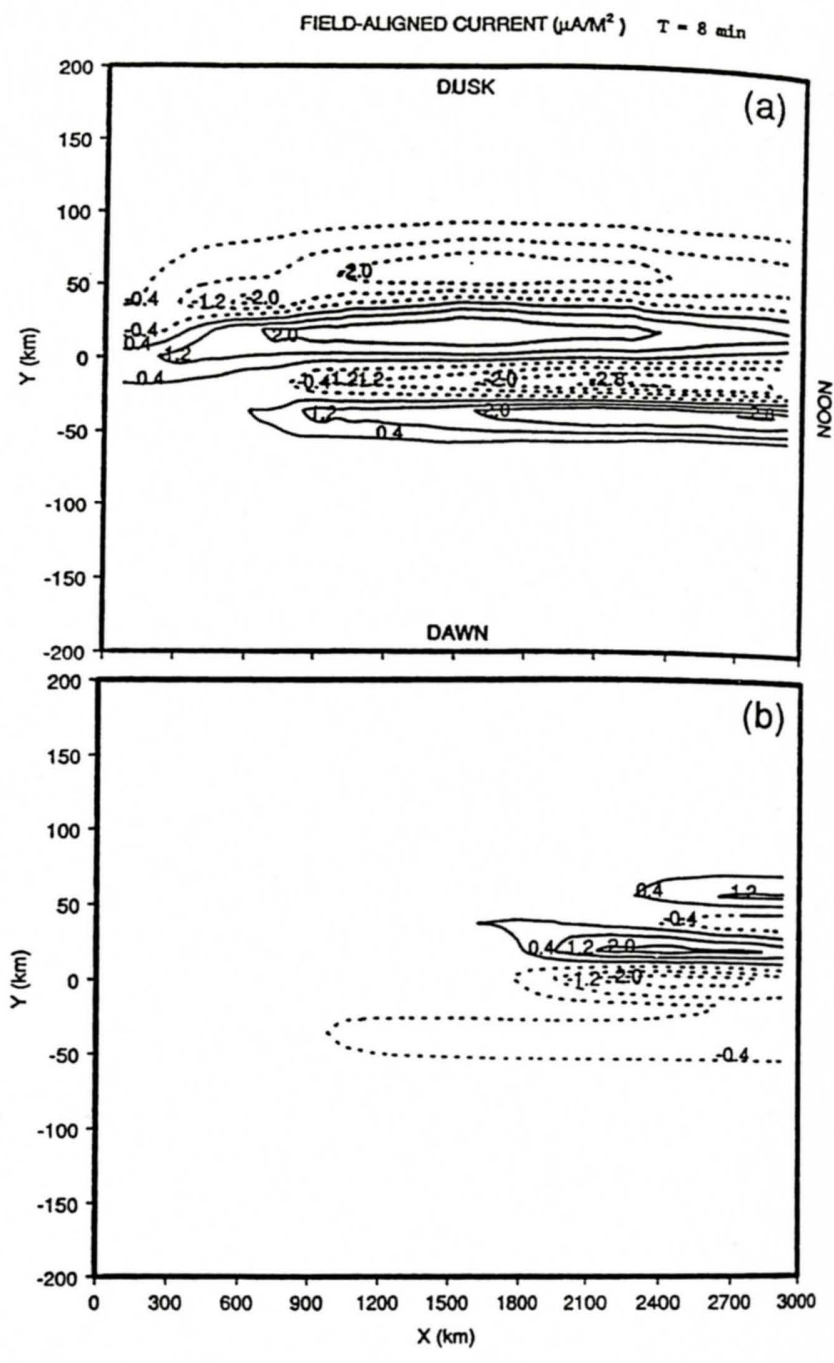

Figure 3. Field-aligned current distribution at the asymptotic steady state for (a) background anti-sunward convection and for (b) sunward convection. The upward currents are represented by dashed contours, while the downward currents are shown as solid contours.

sheet is downflowing, and the sheets have a net duskward displacement. Figure $3 b$ the sunward convection case, is different in several ways, not least of which is that the current sheets only extend one third of the way from noon towards midnight. However, two pairs of current sheets have formed, although their maximum current densities for the dusk pair do not reach the $2 \mu \mathrm{A} / \mathrm{m}^{2}$ found in the Figure 3a case. The current sheets show the same net displacement towards dusk; however, the current sheets are reversed, with the most dawnward sheet being an upward current. The current reversal is due to the reversal of the direction of background convection. Observationally both simulations would produce a pair of visual arcs located in regions where the upward field-aligned currents exceed $0.8 \mu \mathrm{A} / \mathrm{m}^{2}$.

The sunward and antisunward convection cases are not just mirror images of each other. Distinct asymmetries in both the extent and the current carried by the SA are present. Initially, before the shear Alfvén wave is introduced, the two ionospheric systems are symmetric. The initial background conductivities are identical, with a linear decrease in the Hail 
conductivity from $1.5 \mathrm{mho}$ at noon to 0.5 at midnight. Then, the result of the background sunward and anti-sunward convection is to drive a downward and upward current of 0.02 $\mu \mathrm{A} / \mathrm{m}^{2}$, respectively. Once the arcs develop, the orientation of the current sheet pairs is consistent with the imposed electrodynamics, although the existence of two current pairs is unexpected given the single shear wave SA topology. The major issues to be resolved are the noon-midnight extent and the current density differences. Both originate from the convective term in (1). The effect of this convective term is asymmetric between the two cases being considered. For antisunward convection, enhanced electron populations are convected antisunward into regions of reduced conductivity and so enhances its effect on the M-I coupling. In contrast, the sunward convection moves the same enhanced electron populations into regions of larger conductivity, thereby reducing its effect on the M-I coupling process. The net effect of this is only evident after allowing the system to relax towards the asymptotic solution shown in Figures $3 \mathrm{a}$ and $3 \mathrm{~b}$. Having established the asymmetric dependence on the sunward versus antisunward convection, the next subsection investigates the dependence of the asymptotic SA solution on the magnitude of the sunward convection electric field.

\subsection{Dependence on the Sunward Background E Magnitude}

A set of six simulations were carried out to illustrate the dependence of the steady state SA on the magnitude of the sunward convection imposed as the background convection pattern. All six simulations were otherwise identical to the $20-\mathrm{mV} / \mathrm{m}$ simulation discussed in subsection 4.1 . The six simulations were for electric field strengths of $5,10,15,20$, 25 , and $30 \mathrm{mV} / \mathrm{m}$; and the $20-\mathrm{mV} / \mathrm{m}$ case is the same as used in the prior section. Plate 1 and Figures 4 and 5 show, respectively, the two-dimensional steady state distributions of the field-aligned currents, Hall conductances, and Joule heatings $(\mathbf{J} \bullet \mathbf{E})$ for all six simulations. All three parameters show a significant dependence on the electric field strength of the background convection. This dependence is not a linear effect in which the steady state patterns simply scale with the electric field magnitude. The degree of striation, or multiple character, of the SAs increases rapidly from about 1 arc at $|E|<$ $20 \mathrm{mV} / \mathrm{m}$ to 5 arcs at $30 \mathrm{mV} / \mathrm{m}$.

The steady state field-aligned currents are shown in Plate 1. Only part of the simulation region is shown; the entire midnight-noon extent but only $400 \mathrm{~km}$ of the dawn-dusk extent. Outside this region no significant field-aligned current structure is present. Blue colors represent upward currents, while the orange-red colors represents downward currents. White represents regions of currents whose magnitudes are less than $0.05 \mu \mathrm{A} / \mathrm{m}^{2}$. The strongest field-aligned current densities are found in the $30-\mathrm{mV} / \mathrm{m}$ simulation near noon. For this case the currents in the central current sheet pair reach values of $3.6 \mu \mathrm{A} / \mathrm{m}^{2}$. However, the weakest SA current densities are not found in the $5-\mathrm{mV} / \mathrm{m}$ simulation, but rather in the $15-\mathrm{mV} / \mathrm{m}$ case. This trend is shown in Table 1 , where the upward field-aligned current associated with each steady state case has been integrated over an area that has a $400 \mathrm{~km}$ width in the simulation region. The total area over which the integration has been performed is $1.2 \times 10^{12} \mathrm{~m}^{2}$. As the electric field increases from 5 to $15 \mathrm{mV} / \mathrm{m}$, the integrated upward current decreases from $0.916 \times 10^{5}$ to $0.809 \times 10^{5} \mathrm{~A}$.
In each case the weak field-aligned current associated with the background uniform electric field has been subtracted from the arc current system.

The character of the simulation changes form at about 15 $\mathrm{mV} / \mathrm{m}$. Below this electric field value, the SA region is very confined along the central midnight-noon region to $+/-50 \mathrm{~km}$ in the dawn-dusk direction, with strong gradients. Above this electric field strength, the SA region expands to over $+/-100$ $\mathrm{km}$ in the dawn-dusk direction. This trend is even more evident in the Hall conductance patterns of Figure 4 . In addition, the number of current sheets remains at one for electric fields less than $15 \mathrm{mV} / \mathrm{m}$, while 3,4 , and 5 current sheet pairs are discernable for the 20-, 25-, and $30-\mathrm{mV} / \mathrm{m}$ simulations, respectively. The spacing between the current sheets is constant, with a value of $40 \mathrm{~km}$ at $x=0$ (midnight) and $43 \mathrm{~km}$ at $x=3000$ (noon). However, the centers of the current sheets move dawnward by 20 and $10 \mathrm{~km}$, respectively, for the transition from 20 to $25 \mathrm{mV} / \mathrm{m}$ and from 25 to 30 $\mathrm{mV} / \mathrm{m}$. For the case of the antisunward background convection, $|E|=20 \mathrm{mV} / \mathrm{m}$, shown in Figure 3a, the noon and midnight arc spacings are 60 and $55 \mathrm{~km}$, respectively.

The Hall conductances shown in Figure 4 exhibit a very nonlinear variation with $|E|$. A conductance minimum is found for the $20-\mathrm{mV} / \mathrm{m}$ case, with the value just reaching $5 \mathrm{mho}$. At the lowest $|E|$, the conductance peaks at over $7 \mathrm{mho}$, while at $30 \mathrm{mV} / \mathrm{m}$ (the largest $|E|$ shown) the conductance peaks at a little over 6 mho. In addition to this trend, the enhanced conductivity regions for $|E|<20 \mathrm{mV} / \mathrm{m}$ are very narrow, being confined to a single channel. This is not so for the larger $|E|$ cases, where distinct islands of enhanced conductance appear. The net result is that the enhanced conductance, when integrated over the appropriate spatial area, increases rapidly at the high field strengths. Table 1 clearly indicates this trend in which the enhanced conductance, that is, relative to the initial ionospheric conductance, has been integrated over that $400-\mathrm{km}$-wide region. For the $30-\mathrm{mV} / \mathrm{m}$ case the enhanced conductance approaches $80 \%$ of the total initial ionospheric conductance in the integration region.

Combining the enhanced conductances with the associated currents leads to the Joule heating rates for each asymptotic steady state SA simulation. Figure 5 shows these Joule heating rates for the six sunward convection cases. Unlike the field-aligned currents in Plate 1 or the Hall conductances in Figure 4, the Joule heating rates display an increase with the $|E|$. Indeed, this is verified by the integrated Joule heating rates tabulated in Table 1 . The integrated Joule heating rate increases with increasing background electric field strength. For $|E|$ less than $15 \mathrm{mV} / \mathrm{m}$ the rate of increase is very much smaller than for values above $20 \mathrm{mV} / \mathrm{m}$. The local Joule heating rates show an enhancement at noon that has the same trend as the enhanced noon background ionospheric conductances. For the $30-\mathrm{mV} / \mathrm{m}$ simulation, peak Joule heating rates of $7.5 \mathrm{erg} / \mathrm{cm}^{2} \mathrm{~s}$ are obtained.

The Sun-aligned arc structures identified by the current pairs in Plate 1 are shown along a cross section of the arc in Figure 6 , where both the $E_{y}$ electric field component and the fieldaligned current are shown for all six simulations. These cross sections have all been plotted at $X=2400 \mathrm{~km}$ for the asymptotic steady state solution. In the left panel the $E_{y}$ components are plotted on one set of axes, with each case being readily distinguished by the electric field strength at the -250 and $250 \mathrm{~km} Y$ locations. For the 5,10 , and $15 \mathrm{mV} / \mathrm{m}\left|E_{y}\right|$ cases the background electric field has a clear signature of the 

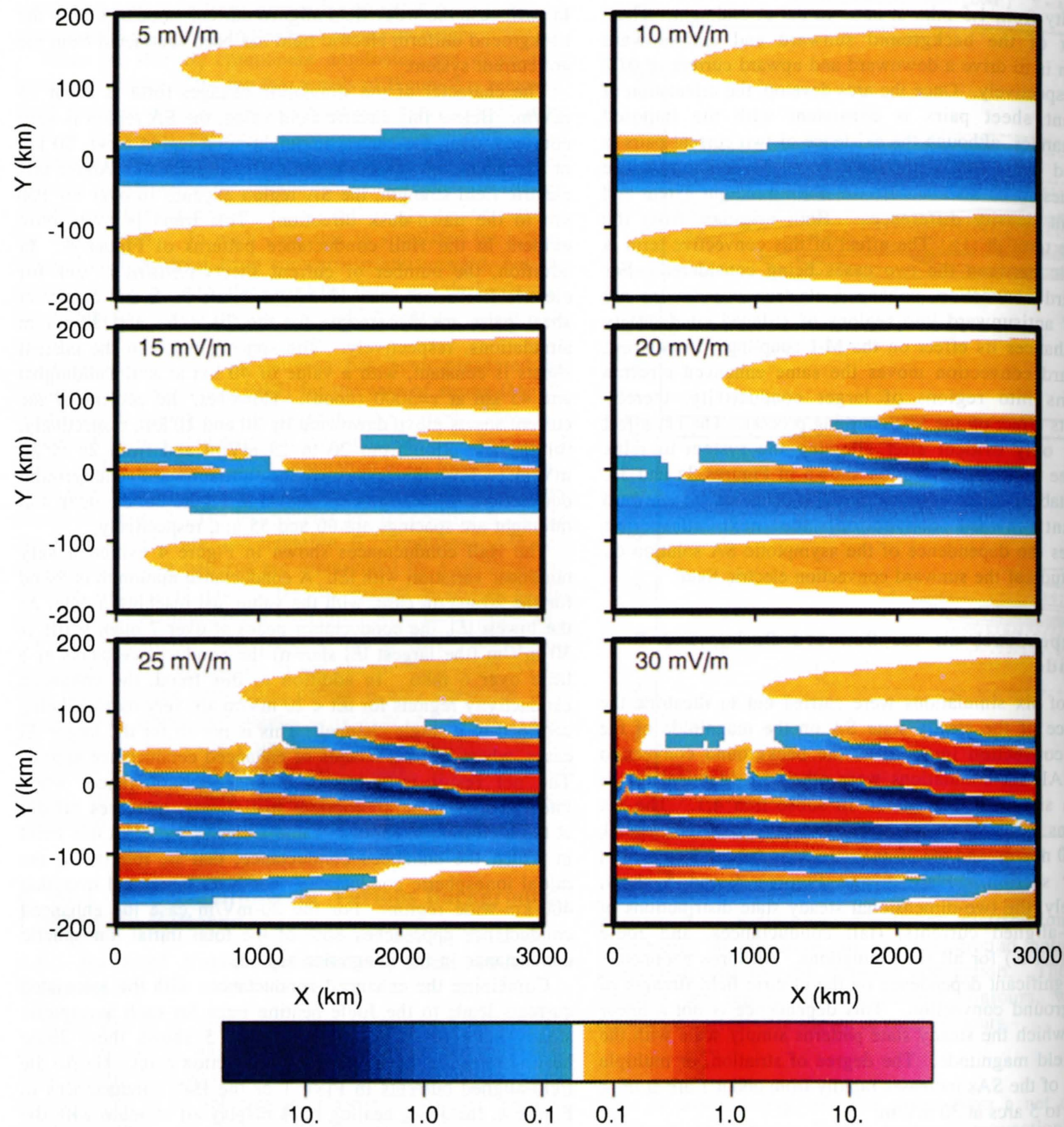

up current $\left(\mu \mathrm{A} / \mathrm{m}^{2}\right) \quad$ down current $\left(\mu \mathrm{A} / \mathrm{m}^{2}\right)$

Plate 1. Field-aligned current distributions at the asymptotic steady state for six different background, sunward, convection electric field strengths. Each panel is labeled with the corresponding electric field magnitude. Upward and downward currents are represented by blue and orange-red colors, respectively, with the units in $\mu \mathrm{A} / \mathrm{m}^{2}$. The white regions have currents whose magnitudes are less than $0.05 \mu \mathrm{A} / \mathrm{m}^{2}$.

shear Alfvén wave structure superimposed upon it (see Figure 1). However, for the larger background electric field cases, the nonlinear M-I coupling caused by the self-consistent ionization changes due to precipitation is very evident. These nonnegligible perturbations are associated with the fieldaligned current sheets shown in Plate 1. The field-aligned currents shown in the panels on the right side of Figure 6 show these current sheets. For the 5-, 10-, and $15-\mathrm{mV} / \mathrm{m}$ simulations these currents are small and dominated by the imposed shear Alfvén wave structure. However, for the 20-, $25-$, and $30-\mathrm{mV} / \mathrm{m}$ cases, multiple current sheets on scales smaller than the imposed shear structure are present, with currents that swamp the original shear current system. The dashed diagonal lines have been drawn through the current peaks and valleys to show that the arc systems maintain a constant spacing and that they move dawnward as the electric field strength increases. The details of both the spacing and dawnward drift are subjects for a follow-up study and will not be addressed further.

A number of revealing conclusions can be drawn from the results in this section. First, the interaction between the magnetosphere and ionosphere is not linear. When the 
HALL CONDUCTANCE (MHO)

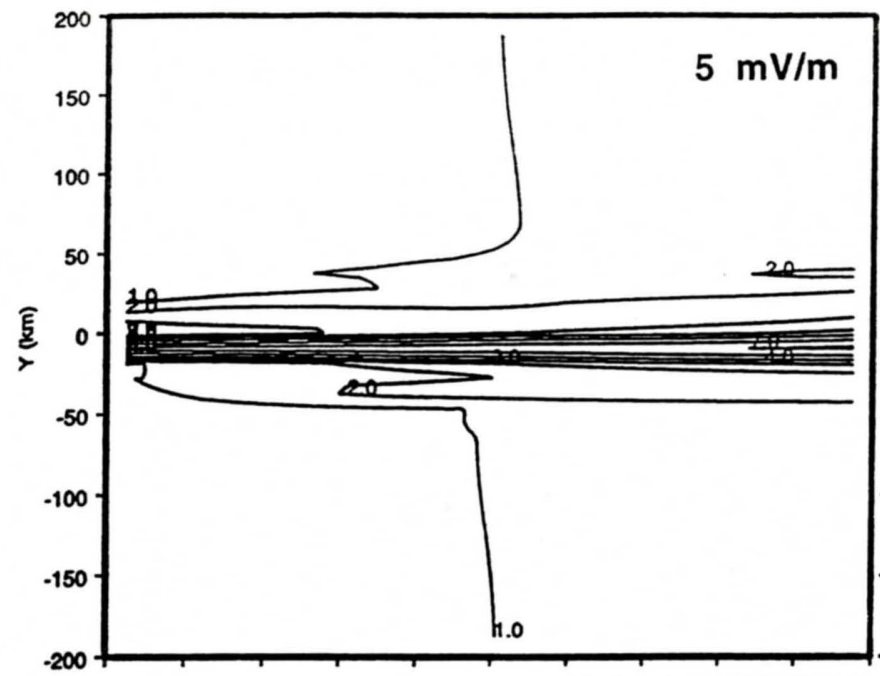

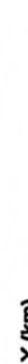

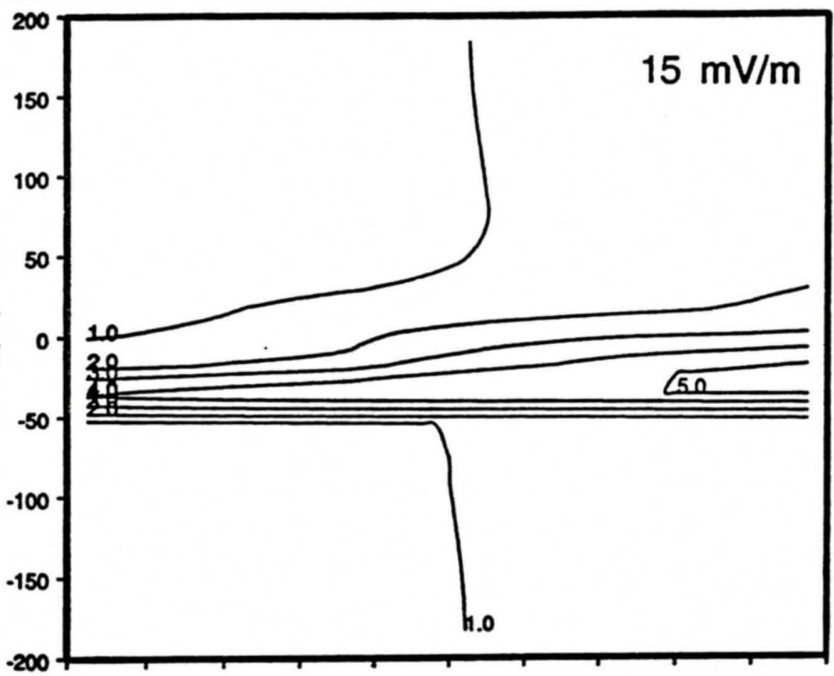

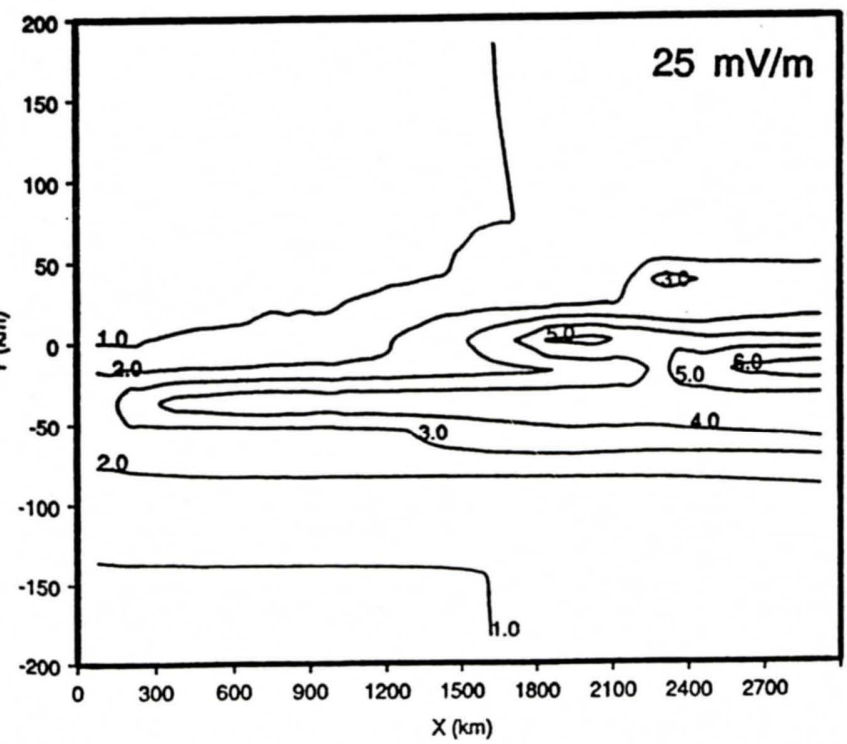

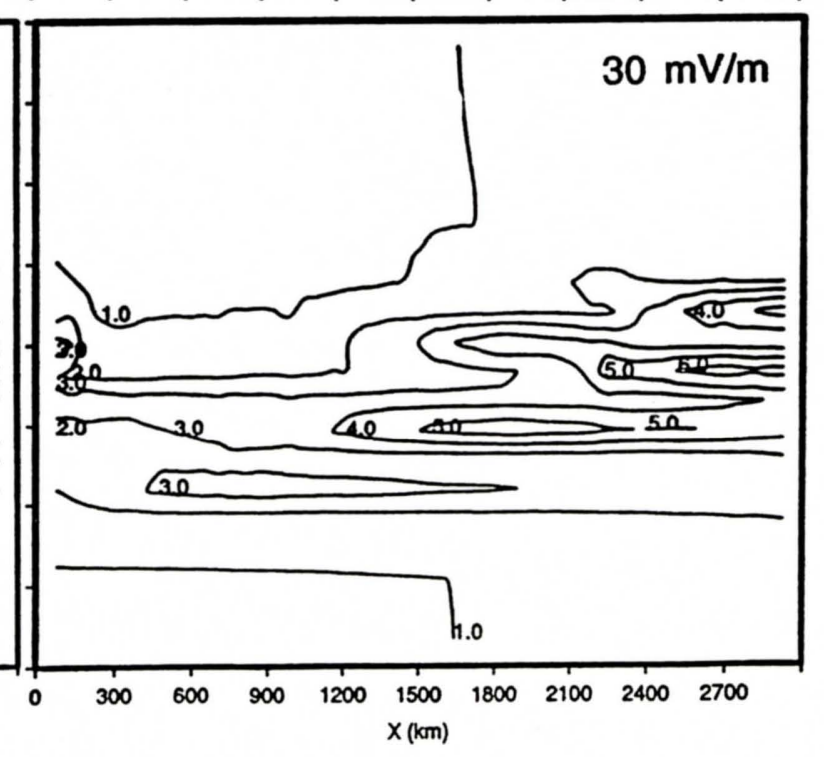

Figure 4. Hall conductances at the asymptotic steady state for the same six background sunward convection electric fields used in Plate 1. The height-integrated Hall conductance contours are labeled in mho. 
JOULE HEATING (ERG/CM² S)
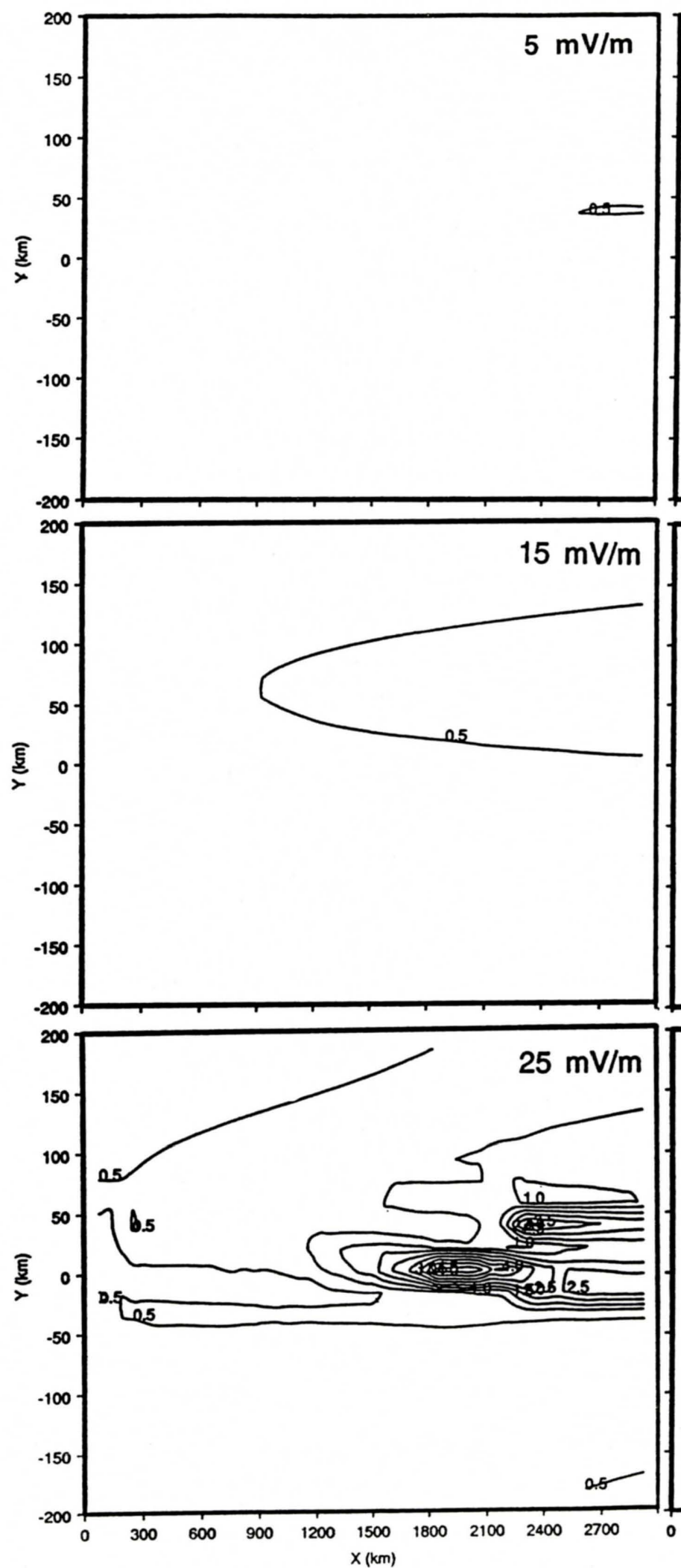

JOULE HEATING (ERG/CM² S)
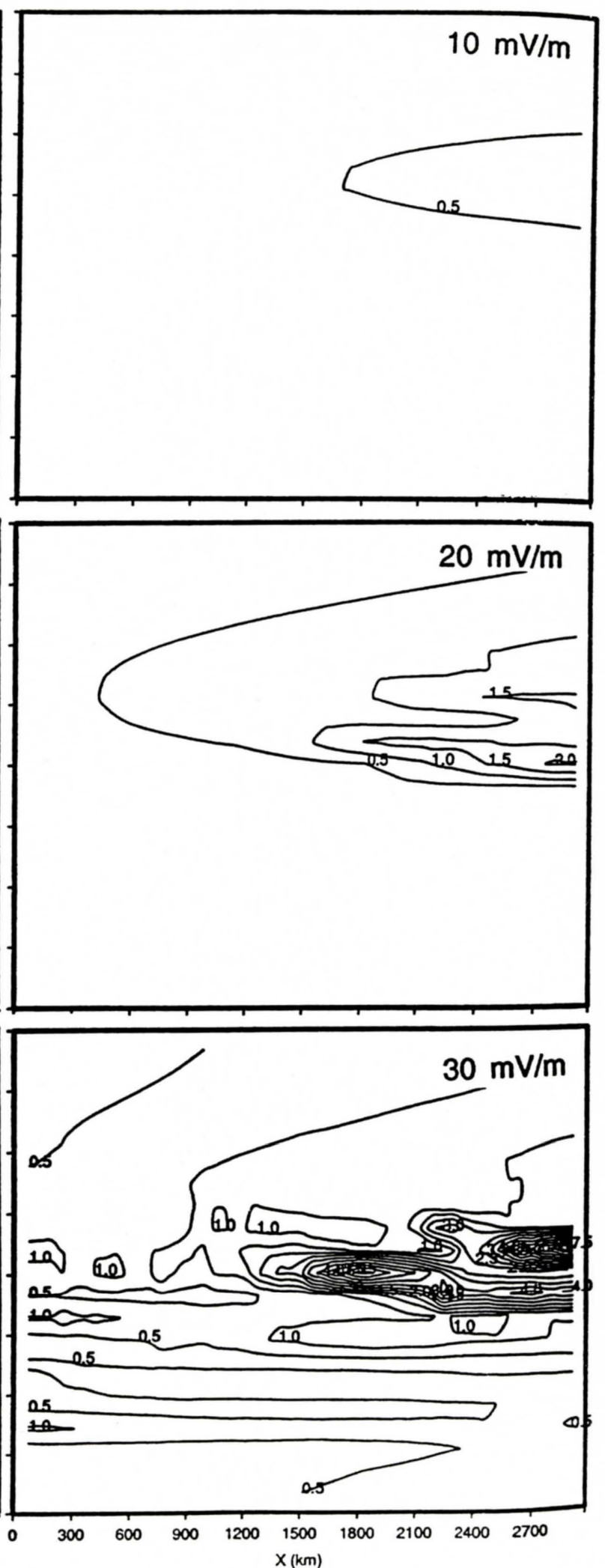

Figure 5. Joule heating rates at the asymptotic steady state for the same six background sunward convection electric fields used in Plate 1. The Joule heating rate contours are labeled in $\mathrm{erg} / \mathrm{cm}^{2} \mathrm{~s}$. 
Table 1. Dependence of Integrated Parameters on the Background $|E|$

\begin{tabular}{cccc}
\hline $\begin{array}{c}\text { Background }|E| \\
\mathrm{mV} / \mathrm{m}\end{array}$ & $\begin{array}{c}\text { Hall } \\
\text { Conductance,* } \\
\text { mho m }^{2}\end{array}$ & $\begin{array}{c}\text { Upward } \\
\text { Current,* } \\
\text { amp }\end{array}$ & $\begin{array}{c}\text { Joule } \\
\text { Heating,* } \\
\text { erg/s }\end{array}$ \\
\hline 5 & $4.40 \mathrm{E} 11$ & $0.916 \mathrm{E} 5$ & $1.11 \mathrm{E} 15$ \\
10 & $4.26 \mathrm{E} 11$ & $0.890 \mathrm{E} 5$ & $1.13 \mathrm{E} 15$ \\
15 & $4.39 \mathrm{E} 11$ & $0.809 \mathrm{E} 5$ & $1.18 \mathrm{E} 15$ \\
20 & $5.55 \mathrm{E} 11$ & $1.300 \mathrm{E} 5$ & $1.63 \mathrm{E} 15$ \\
25 & $8.39 \mathrm{E} 11$ & $2.680 \mathrm{E} 5$ & $3.05 \mathrm{E} 15$ \\
30 & $9.29 \mathrm{E} 11$ & $3.580 \mathrm{E5}$ & $4.38 \mathrm{E} 15$ \\
\hline
\end{tabular}

*Background level subtracted then integrated over $\{-200$ $\mathrm{km}<X<200 \mathrm{~km}, 0<Y<3000 \mathrm{~km}\}$.

background convection strength exceeds a threshold, the currents, conductances, and Joule heating rates increase dramatically. Furthermore, the M-I current system associated with the imposed shear Alfvén wave structure becomes striated and up to 5 current sheet pairs form for the largest background electric field used in this study. These striations are conclusive evidence that a linear superposition of background and arc electric fields is an incorrect way to view the M-I coupling because the ionosphere can dynamically respond to changing currents. The currents are all closed locally within the imposed Alfvén wave structure.

\subsection{Dependence on Three-Cell Background Convection}

The three-cell convection pattern occurs under weakly northward IMF conditions when the $B_{y}$ component is larger than the $B_{z}$ component. Figure 2 shows a schematic representation of this convection pattern as well as the adopted convection model for our simulations. The adopted model emphasizes the very weak shear convection rotation that occurs at the middle of the central cell of the three-cell pattern. In this set of simulations the imposed Alfvén wave shear reversal is parallel to the symmetry axis of the convection rotation in the background convection. The magnitude of the background electric field has also been chosen to be consistent with the IMF conditions of $B_{z}$ weakly northward. The $B_{y}$ negative and positive background convection patterns are mirror images of each other about the noon-midnight axis (i.e., see Figure 2). However, once the Sun-aligned arc shear is introduced the two cases are no longer symmetric. This is clearly seen in the results of the two simulations shown in Figures $7 \mathrm{a}$ and $7 \mathrm{~b}$ for the $B_{y}$ positive and negative cases, respectively.

Figure 7 shows dawn-dusk cross sections of the steady state solutions at $X=1500 \mathrm{~km}$ for the $E_{y}$ electric field component, Joule heating rate, Hall conductance, and field-aligned current. The comparison of the two $E_{y}$ components shows that the interaction of the Alfvén wave with the ionosphere and its imposed background convection leads to appreciably different electric field patterns. In the $B_{y}$ positive situation the resulting electric field is positive in the dawn sector and

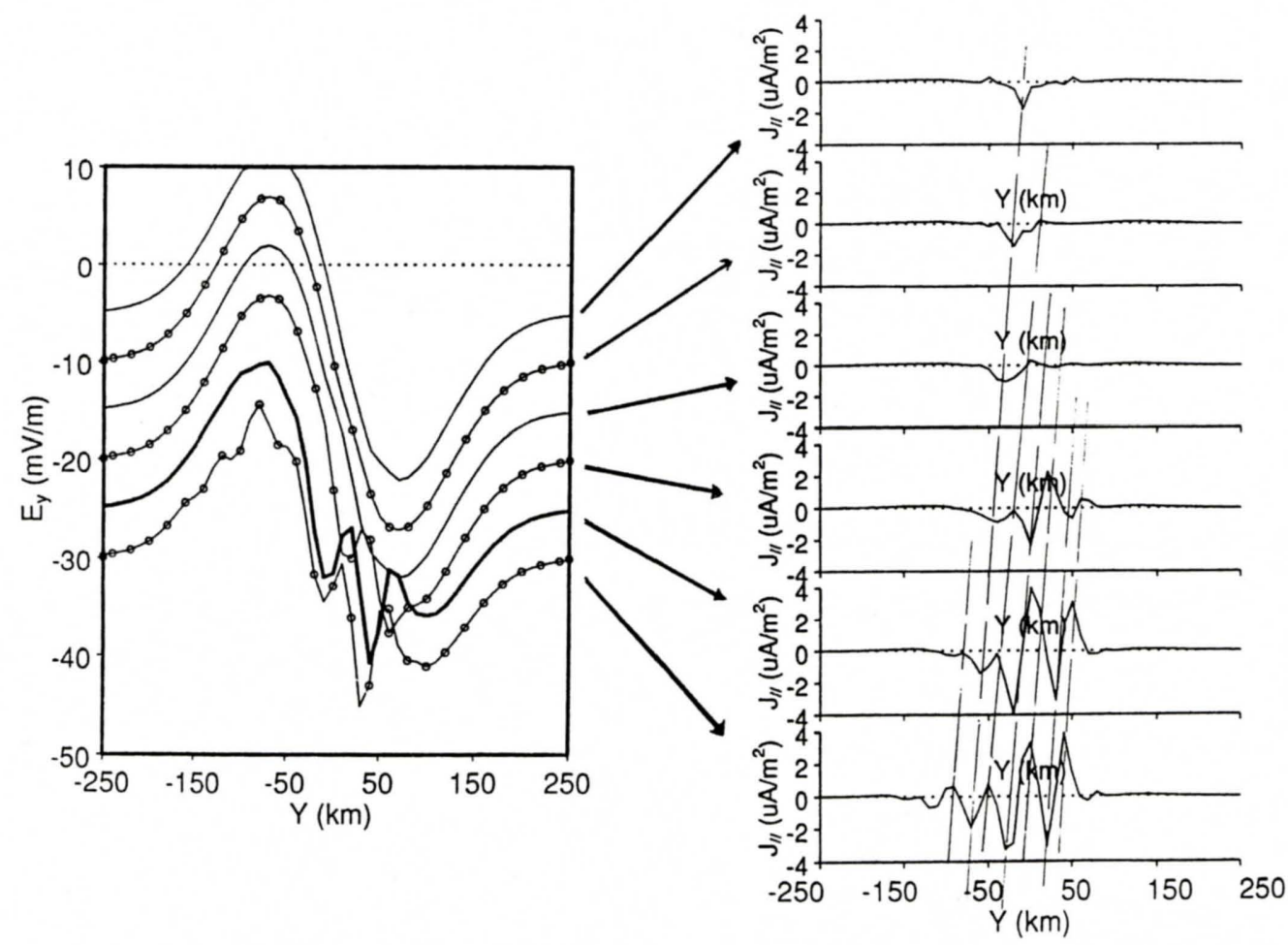

Figure 6. $E_{y}$ electric field dawn-dusk variation at $X=2400 \mathrm{~km}$ (left panel) and the corresponding fieldaligned currents (stacked right panels) at the asymptotic steady state for the six different background electric field strengths used in Plate 1. In the left panel the background electric field strength can be read from the $E_{y}$ scale at $Y=-250 \mathrm{~km}$. Diagonal dashed lines (right panel) are used to join the peaks and troughs in the fieldaligned currents for the six cases to show the constancy of the spacing between the upward and downward current sheets. 

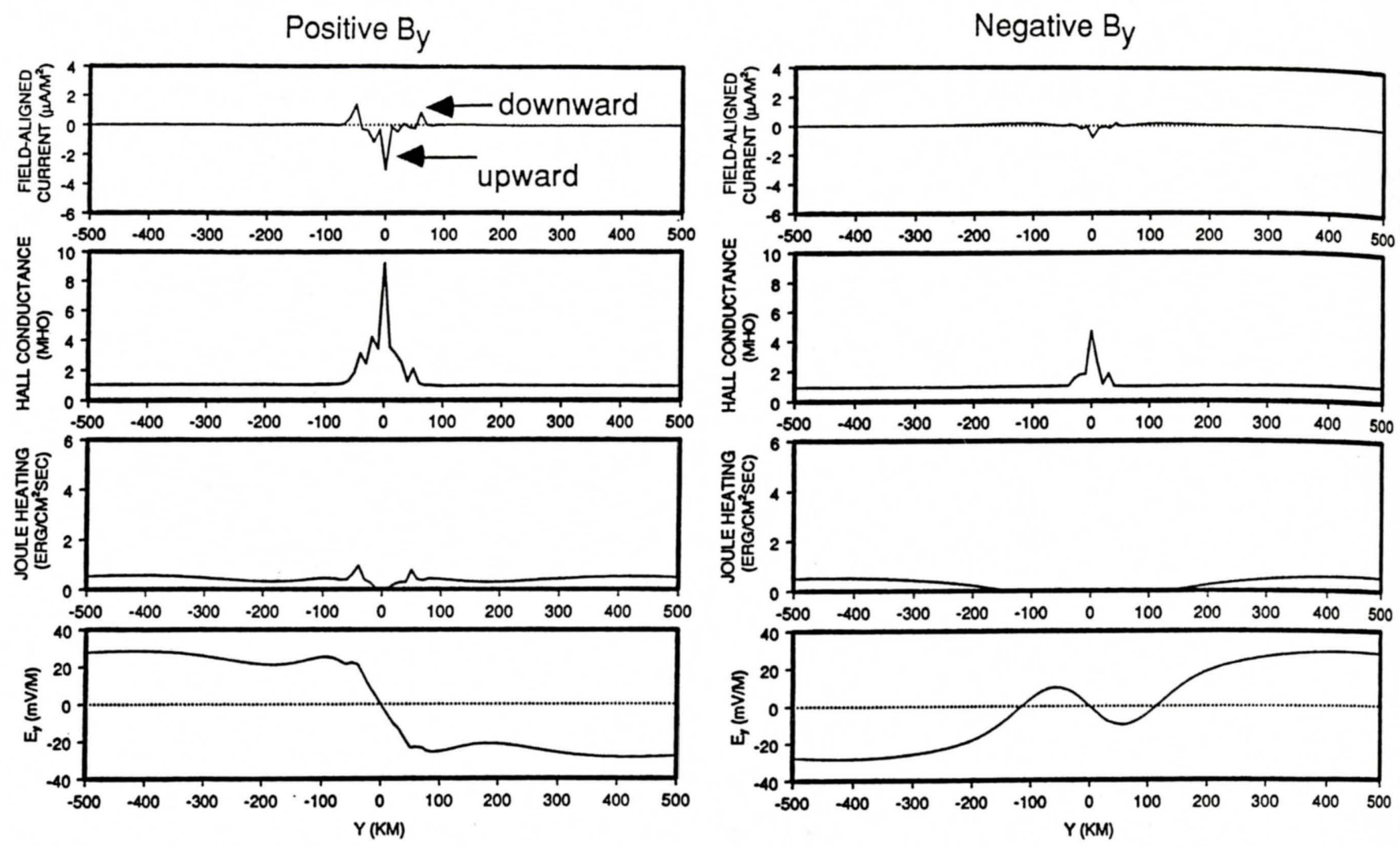

a)

Figure 7. Dawn-dusk variation of the field-aligned current, Hall conductance, Joule heating rate, and $E_{y}$ at $X=2400 \mathrm{~km}$ for three-cell convection with (left) positive $B_{y}$ and (right) negative $B_{y}$ interplanetary magnetic field conditions. The cross sections correspond to the asymptotic steady state.

negative in the dusk sector (Figure 7a), whereas for the $B_{y}$ negative case, both positive and negative electric fields are present in the dawn and dusk sectors. The steady state fieldaligned currents both show an upward current at the middle of the imposed shear structure. However, the upward current is 4 times larger in the $B_{y}$ positive case. For the $B_{y}$ positive case, two regions of downward current are present on either side of the upward current channel. For the $B_{y}$ negative case the return currents are more widely distributed on each side. The Hall conductance shows a strong enhancement over the background value of 1 mho at the center of the imposed shear Alfvén wave. However, the enhancement is greater for the $B_{y}$ positive simulation (Figure 7a).

The net energy dissipated in the two cases is a more telling demonstration of the difference between the two simulations. For the $B_{y}$ negative simulation (Figure $7 \mathrm{~b}$ ) the Joule heating rate is smallest in the region where the imposed shear is located. The Joule heating follows the $Y$ variation of the background electric field magnitude. The arc electrodynamics does not lead to a significant Joule heating. For the $B_{y}$ positive simulation this is not the case; structured Joule heating is present within the arc region that peaks at twice the value reached by the background Joule heating rate. A very simplistic way of viewing the difference between these two simulations is that in the $B_{y}$ positive case, the imposed shear $E_{y}$ is in the same spatial phase as the background $E_{y}$, thus leading to an enhanced $E_{y}$, whereas in the $B_{y}$ negative case the opposite $E_{y}$ distribution leads to a destructive superposition.
The net effect is that the $B_{y}$ positive case has enhanced electrodynamic parameters (i.e., field-aligned current, Hall conductance, Joule heating rate, etc.) in the arc region. However, this "linear superposition" is an over simplification and does not include the nonlinear M-I interaction which, although weak in this particular simulation, is nonetheless present. For the $B_{y}$ positive case this nonlinear interaction is responsible for the fine structure in the field-aligned current and Hall conductance.

\subsection{Dependence on the Distorted Two-Cell Background Convection}

All three prior representations of the background convection have a strong symmetry relative to the noonmidnight meridian. Each background pattern has equipotentials that are noon-midnight aligned, and which are also parallel to the axis of the imposed Alfvén shear structure. The distorted two-cell convection pattern, by its very name, does not possess this symmetry. Figure 2 shows a schematic representation of the distorted two-cell patterns in the polar cap from Heppner and Maynard [1987]. For weakly northward IMF conditions, when the $B_{y}$ component is significantly larger than the $B_{z}$ component, the equipotentials are oriented obliquely to the noon-midnight axis. In the simulation it is this feature that is modeled, as shown in Figure 2. The background convection is at $45 \mathrm{deg}$ to that imposed by the Alfvén shear structure. 
Figure 8 shows the results of the SA simulation at a steady state time for the same parameters as shown in Figure 7. The left panel shows the field-aligned current, Hall conductance, Joule heating, and $E_{y}$ for a strong $B_{y}$ positive IMF, while the right panel shows the same parameters for a strong $B_{y}$ negative IMF. The convection is antisunward in both cases, with a duskward component for the $B_{y}$ positive case (in the positive $Y$ direction) and a dawnward component for the $B_{y}$ negative case (in the negative $Y$ direction). In both cases the magnitudes of the electric fields and convection velocities are consistent with the distorted two-cell conditions of $B_{z}$ small (see $E_{y}$ in the bottom panels of Figure 8 ). The $B_{y}$ positive case shows a greater degree of structuring in the field-aligned current, Hall conductance, and Joule heating terms than is seen in the $B_{y}$ negative case. All the structuring occurs on the dawnside of the imposed shear region. The Joule heating peaks in this region of structure. On the duskside of the shear region the parameters vary smoothly with the highest Hall conductance being in this region. For the $B_{y}$ negative case the situation is reversed, although the peak Hall conductance is still located in the dawn sector of the imposed shear. However, in the negative $B_{y}$ case the enhanced Joule heating is found in the same location as for the $B_{y}$ positive case; namely, in the dusk sector of the shear structure. Hence the features associated with the strong cross-arc convection are not mirror images of each other.

In both of the distorted two-cell convection cases the result of the background cross-arc convection is to extend the dawndusk region over which the imposed shear is effective. This can be seen by comparing the three-cell (Figure 7) with the distorted two-cell (Figure 8) Hall conductances. For the three- cell cases the enhanced Hall conductances are located between -70 and $70 \mathrm{~km}$, whereas for the distorted two-cell cases they extend from over -100 to $+100 \mathrm{~km}$.

\section{Conclusions}

In this study we simulated the ionospheric asymptotic steady state of Sun-aligned arc formation for different background electric field conditions using a coupled M-I model. The background convection patterns are all, to zerothorder, approximations of real polar cap convection patterns. The magnitude of the electric fields and orientations are also consistent with observations. For each simulation an initial Alfvén shear is imposed on the ionosphere from the magnetosphere and the ensuing nonlinear M-I coupling is followed. In the simulations, only the ionosphere responds dynamically to changes in the precipitation associated with the upward currents. The simulation results show a large diversity and hence dependence on the background convection. The main results are summarized as follows:

1. For background electric field strengths less than 15 $\mathrm{mV} / \mathrm{m}$, the imposed shear structure produces current systems that close locally, that is, within the shear structure.

2. For background electric field strengths greater than 15 $\mathrm{mV} / \mathrm{m}$, a distinct nonlinear coupling occurs, the current closure region extends beyond the imposed structure, and finescale current sheets form.

3. The fine structure, which is characterized by sheets of upward and downward currents, has a characteristic spacing that is independent of the magnitude of the background electric field.
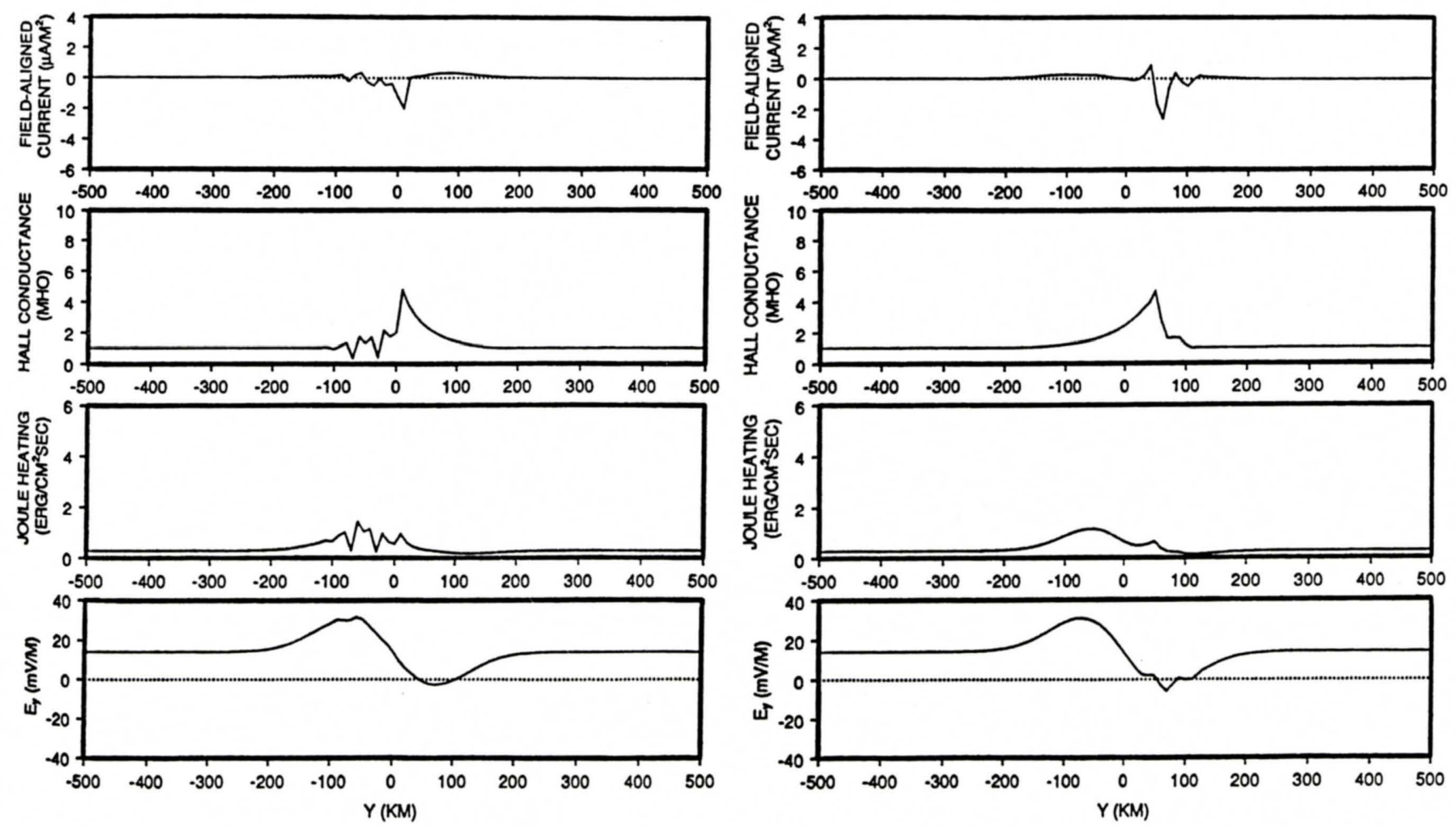

a)

Figure 8. Dawn-dusk variation of the field-aligned current, Hall conductance, Joule heating rate, and $E_{y}$ at $X=2400 \mathrm{~km}$ for distorted two-cell convection with (left) positive $B_{y}$ and (right) negative $B_{y}$ interplanetary magnetic field conditions. The cross sections correspond to the asymptotic steady state. 
4. Gradients in the background electric field component across the arc $\left(d E_{y} / d Y\right)$, which are associated with three-cell convection and strong IMF $B_{y}$ conditions, introduce asymmetries in the SA features. The largest currents, Hall conductances, and Joule heating rates are predicted for positive $B_{y}$ conditions.

5. For the case of plasma convection across the SA structure (distorted two-cell), the largest currents, Hall conductances, and Joule heating rates occur for the case of dawn-to-dusk convection. This asymmetry is also the largest for positive $B_{y}$ IMF conditions.

Our results indicate that SA could form in association with all the proposed northward IMF convection patterns. However, for similar electric field magnitudes, different SA structures form in response to the different background convection patterns. A prediction is made of a threshold at which a transition from a single arc to multiple arcs occurs. However, our threshold calculation was done for only one set of ionospheric conductivities and magnetospheric coefficients. Therefore follow-up work will be required to find the full importance of this threshold. For other cases, our simulations imply that a stronger M-I coupling will occur for positive $B_{y}$ IMF conditions than for negative $B_{y}$ cases. With regard to cross-arc drifts our simulations indicate that dawn-todusk plasma convection generates larger currents, conductances, and Joule heating rates than dusk-to-dawn convection.

These predictions have been carried out for the northern hemisphere only. In the southern hemisphere the ionospheric convection patterns have the opposite dependence on the IMF $B_{y}$ component. If one assumes that the imposed shear Alfvén wave structure is identical to that used in the northern hemisphere, then the SA will have an IMF $B_{y}$ negative preference in the southern hemisphere.

Acknowledgment. This research was supported in part by NASA grant NAG5-1484 and NSF grant ATM-89-13230 to Utah State University.

The Editor thanks R. J. Moffett and another referee for their assistance in evaluating this paper.

\section{References}

Akasofu, S.-I., The development of the auroral substorm, Planet. Space Sci., 12, 273, 1964.

Berkey, T., L. L. Cogger, S. Ismail, and Y. Kamide, Evidence for a correlation between sun-aligned arcs and the interplanetary magnetic field direction, Geophys. Res. Lett., 3, 145, 1976.

Burch, J. L., et al., IMF $B_{y}$-dependent plasma flow and Birkeland currents in the dayside magnetosphere, 1, Dynamics Explorer observations, J. Geophys. Res., 90, 1577, 1985.

Burke, W. J., M. C. Kelley, R. C. Sagalyn, M. Smiddy, and S. T. Lai, Polar cap electric field structures with a northward interplanetary magnetic field, Geophys. Res. Lett., 6, 21, 1979.

Burke, W. J., M. S. Gussenhoven, M. C. Kelley, D. A. Hardy, and F. J. Rich, Electric and magnetic field characteristics of discrete arcs in the polar cap, J. Geophys. Res., 87, 2431, 1982.

Carlson, H. C., Jr., V. B. Wickwar, E. J. Weber, J. Buchau, J. G. Moore, and W. Whiting, Plasma characteristics of polar cap $F$-layer arcs, Geophys. Res. Lett., 11, 895, 1984.

Carlson, H. C., R. A. Heelis, E. J. Weber, and J. R. Sharber, Mesoscale convection patterns during northward interplanetary magnetic field, J. Geophys. Res., 93, 14,501, 1988.

Chiu, Y. T., Formation of polar cap arcs, Geophys. Res. Lett., 16, 743, 1989.

Chiu, Y. T., N. U. Crooker, and D. J. Gorney, Model of oval and polar cap arc configurations, J. Geophys. Res., 90, 5153, 1985.
Davis, T. N., The morphology of the polar aurora, J. Geophys. Res., 65, 3497, 1960.

Davis, T. N., Negative correlation between polar cap visual aurora and magnetic activity, J. Geophys. Res., 68, 4447, 1963.

Denholm, J. V., and F. R. Bond, Orientation of polar auroras, Aust. J. Phys., 14, 193, 1961.

Frank, L. A., J. D. Craven, J. L. Burch, and J. D. Winningham, Polar views of the Earth's aurora with Dynamic Explorer, Geophys. Res. Lett., 9, 1001, 1982.

Frank, L. A., et al., The theta aurora, J. Geophys. Res., 91, 3177, 1986.

Gussenhoven, M. S., Extremely high latitude auroras, J. Geophys. Res., $87,2401,1982$.

Hardy, D. A., W. J. Burke, and M. S. Gussenhoven, DMSP optical and electron measurements in the vicinity of polar cap arcs, J. Geophys. Res., 87, 2413, 1982.

Heppner, J. P., and N. C. Maynard, Empirical high-latitude electric field models, J. Geophys. Res., 92, 4467-4489, 1987.

Hoffman, R. A., R. A. Heelis, and J. S. Prasad, A Sun-aligned arc observed by CMSP and AE-C, J. Geophys. Res., 90, 9697, 1985.

Ismail, S., and C.-I. Meng, A classification of polar cap auroral arcs, Planet. Space Sci., 30, 319, 1982.

Ismail, S., D. D. Wallis, and L. L. Cogger, Characteristics of polar cap Sun-aligned arcs, J. Geophys. Res., 82, 4741, 1977.

Kan, J. R., and W. J. Burke, A theoretical model of polar cap auroral arcs, J. Geophys. Res., 90, 4171, 1985.

Lassen, K., and C. Danielsen, Quiet time pattern of auroral arcs for different directions of the interplanetary magnetic field in the $Y-Z$ plane, J. Geophys. Res., 83, 5277, 1978.

Lyons, L. R., Generation of large-scale regions of auroral currents, electric potentials, and precipitation by the divergence of the convection electric field, J. Geophys. Res., 85, 17-24, 1980.

Maezawa, K., Magnetospheric convection induced by the positive and negative $Z$ component of the interplanetary magnetic field: Quantitative analysis using polar cap magnetic records, J. Geophys. Res., 81, 2289, 1976.

Makita, K., C.-I. Meng, and S.-I. Akasofu, Transpolar auroras, their particle precipitation, and IMF $B_{y}$ component, J. Geophys. Res., 96, 14,085, 1991.

Marklund, G. T., and L. G. Blomberg, On the influence of localized electric fields and field-aligned currents associated with polar arcs on the global potential distribution, J. Geophys. Res., 96, 13,977, 1991.

Mende, S. B., J. H. Doolittle, R. M. Robinson, R. R. Vondrak, and F. J. Rich, Plasma drifts associated with a system of Sun-aligned arcs in the polar cap, J. Geophys. Res., 93, 256, 1988.

Meng, C.-I., Polar cap arcs and the plasma sheet, Geophys. Res. Lett., 8, 273, 1981.

Murphree, J. S., C. D. Anger, and L. L. Cogger, The instantaneous relationship between polar cap and oval auroras at times of northward interplanetary magnetic field, Can. J. Phys., 60, 349, 1982.

Nielsen, E., J. D. Craven, L. A. Frank, and R. A. Heelis, Ionospheric flows associated with a transpolar arc, J. Geophys. Res., 95, 21,169, 1990.

Potemra, T. A., L. J. Zanetti, P. F. Bythrow, T. A. Lui, and T. Iijima, Bydependent convection patterns during northward interplanetary magnetic field, J. Geophys. Res., 89, 9753, 1984.

Rasmussen, C. E., and R. W. Schunk, Ionospheric convection driven by NBZ currents, J. Geophys. Res., 92, 4491, 1987.

Reiff, P. H., and J. L. Burch, IMF By-dependent plasma flow and Birkeland currents in the dayside magnetosphere, 2, A global model for northward and southward IMF, J Geophys. Res., 90, 1595-1609, 1985.

Rich, F. J., D. A. Hardy, R. H. Redus, and M. S. Gussenhoven, Northward IMF and patterns of high-latitude precipitation and fieldaligned currents: The February 1986 storm, J. Geophys. Res., 95, 7893, 1990.

Russell, C. T., The configuration of the magnetosphere, in Critical Problems of Magnetospheric Physics, vol. 1, edited by E. R. Dyer, p. 1149, National Academy of Sciences, Washington, D. C., 1972. 
Valladares, C. E., and H. C. Carlson, Jr., The electrodynamic, thermal, and energetic character of intense Sun-aligned arcs in the polar cap. J. Geophys. Res., 96, 1379, 1991.

Weber, E. J., and J. Buchau, Polar cap F-layer auroras, Geophys. Res. Lett., 8, 125, 1981.

Weill, G., Aspects de l'aurore observée á la base Dumont-d'Urville en Terre Adelie, C. R. Acad. Sci., 246, 2925, 1958.

Zhu, L., J. J. Sojka, R. W. Schunk, and D. J. Crain, A time-dependent model of polar cap arcs, J. Geophys. Res., 98, 6139, 1993a.

Zhu, L., J. J. Sojka, R. W. Schunk, and D. J. Crain, Influence of horizontal inhomogeneity in the ionosphere on the reflection of Alfvén waves, Geophys. Res. Lett., 20, 313-316, 1993b.

D. J. Crain, R. W. Schunk, J. J. Sojka, and L. Zhu, Center for Atmospheric and Space Sciences, Utah State University, Logan, UT 84322-4405. (e-mail: crain@ozone.cass.usu.edu; schunk@cc.usu.edu; fasojka@sojka.cass.usu.edu; zhu@cc.usu.edu)

(Received April 27, 1993; revised August 5, 1993;

accepted September 8, 1993) 